
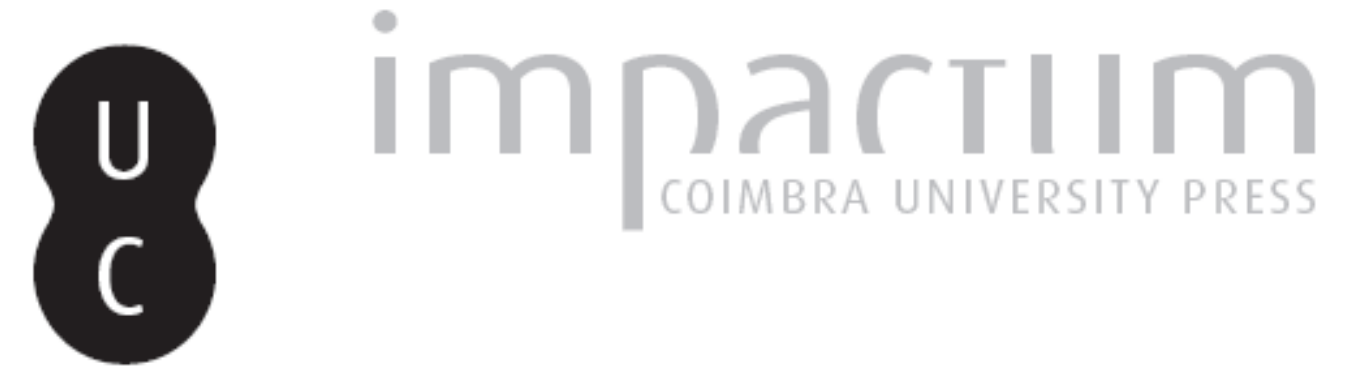

\title{
El "vigilante de la esquina": el rol de la nostalgia en la construcción de relatos policiales argentinos
}

Autor(es): $\quad$ Sirimarco, Mariana

Publicado por: Imprensa da Universidade de Coimbra

URL persistente:

URI:http://hdl.handle.net/10316.2/43418

DOI:

DOI:http://doi.org/10.14195/2182-7982_34_2

Accessed : $\quad$ 26-Apr-2023 13:57:35

A navegação consulta e descarregamento dos títulos inseridos nas Bibliotecas Digitais UC Digitalis, UC Pombalina e UC Impactum, pressupõem a aceitação plena e sem reservas dos Termos e Condições de Uso destas Bibliotecas Digitais, disponíveis em https://digitalis.uc.pt/pt-pt/termos.

Conforme exposto nos referidos Termos e Condições de Uso, o descarregamento de títulos de acesso restrito requer uma licença válida de autorização devendo o utilizador aceder ao(s) documento(s) a partir de um endereço de IP da instituição detentora da supramencionada licença.

Ao utilizador é apenas permitido o descarregamento para uso pessoal, pelo que o emprego do(s) título(s) descarregado(s) para outro fim, designadamente comercial, carece de autorização do respetivo autor ou editor da obra.

Na medida em que todas as obras da UC Digitalis se encontram protegidas pelo Código do Direito de Autor e Direitos Conexos e demais legislação aplicável, toda a cópia, parcial ou total, deste documento, nos casos em que é legalmente admitida, deverá conter ou fazer-se acompanhar por este aviso.

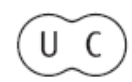




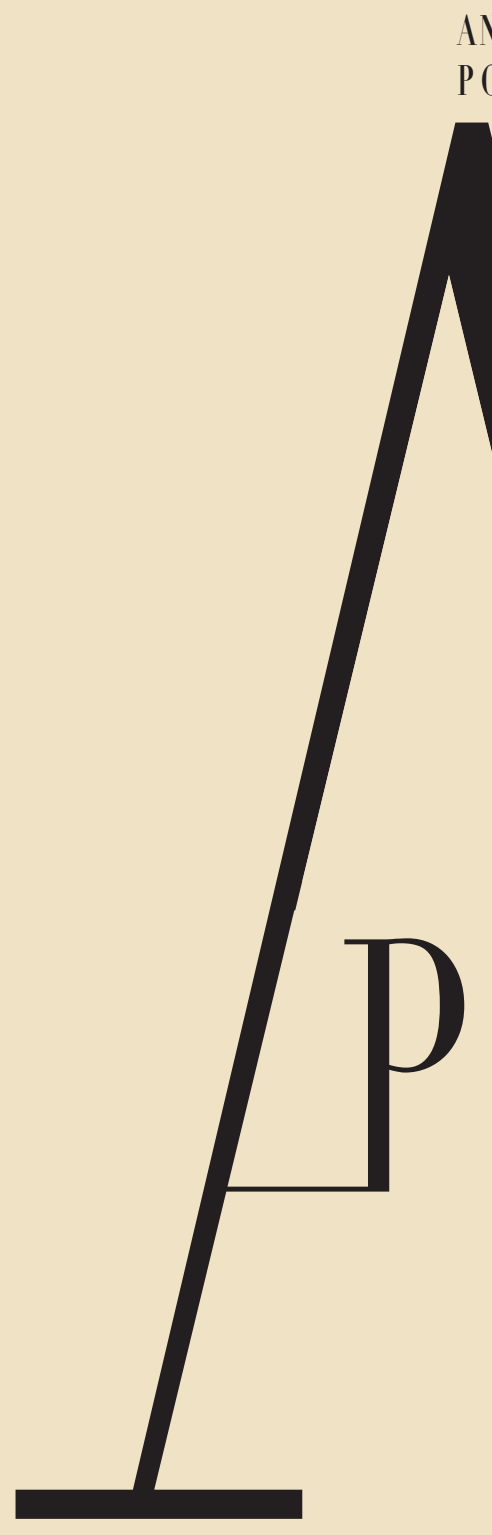

IITROPOLOGIA

PORTUGUESA 


\section{El "vigilante de la esquina". El rol de la nostalgia en la construcción de relatos policiales argentinos}

\section{The "street corner policeman". The role of nostalgia in the construction of Argentinean police stories}

\section{Mariana Sirimarco ${ }^{1 *}$}

\section{Resumen}

Los libros de memorias juegan un rol importante en la literatura escrita por policías. Sobresalen aquí los relatos del "vigilante de la esquina", que muestran al policía de antaño y su relación de confianza con la comunidad.

En este artículo, se analizan las conexiones entre pasado, memoria y emoción que subyacen a la construcción de este relato, proponiéndose que la nostalgia es una herramienta inherente a la construcción de un determinado sentido del tiempo. Examinar el relato del "vigilante de la esquina" implicará analizar los valores con que la agencia policial se representa y rescatar el rol que las emociones juegan en la reproducción de las tradiciones institucionales.

Palabras clave: "Vigilante de la esquina"; policía; pasado; nostalgia; emoción.

\begin{abstract}
Memoirs have an important role in the literature written by policemen. Stories about the "street corner policeman" stand out among them, showing the policemen of old times and their trusty relation with community. In this paper, the connections between past, memory and emotion that underlie the construction of this particular story are analyzed, proposing that nostalgia is an inherent tool to the construction of a certain flow of time. Examining the "street corner policeman" story will imply analyzing the values with which the police institution represents itself and rescuing the role that emotions play in the reproduction of institutional traditions.
\end{abstract}

Key words: "Street corner policeman"; police; past; nostalgia; emotion. 
nuestras vidas, de nuestros pasos, velando nuestros sueños, cuidando a su

En febrero de 2009, el teniente Aldo Roberto Garrido fue muerto mientras intentaba reducir a dos delincuentes en un negocio de la localidad de San Isidro. Pertenecía a la Policía de la Provincia de Buenos Aires (PPBA) y patrullaba la misma zona desde hacía 26 años.

La noticia de su muerte llegó a la prensa del día siguiente. Podría haber sido el recuento frío de otro policía caído en acto de servicio, pero enseguida fue mucho más que eso. Ese día, uno de los diarios principales de Buenos Aires abrió la ola de homenajes con la carta de un lector:

Ayer, a las 8.30 compartimos un saludo, un buen día de vereda a vereda, y una broma de fútbol, como casi todos los días. Yo apuré mi cortado en "Coquito", y me fui rápido a la cerrajería para no llegar tarde. El siguió su recorrido rutinario: "Cómo estuvieron las vacaciones"; "qué bronceada que estás"; "cómo están los chicos"; "qué linda te quedó la nueva vidriera". Y así, uno a uno. Él estaba al tanto de

\footnotetext{
1 La PPBA, como su nombre lo indica, cumple funciones de seguridad pública en el territorio de la provincia de Buenos Aires, la más grande y densamente poblada de la República Argentina. Es, por esto, la mayor fuerza policial del país. A lo largo de este trabajo se harán referencias a ésta y a la Policía Federal Argentina (PFA) indistintamente, al entenderse que lo analizado aquí hace a la cuestión policial como tópico general. Esta última ejerce su función a través de delegaciones a lo largo del país y, conjuntamente con la Policía Metropolitana, en la Ciudad Autónoma de Buenos Aires, capital de la Argentina.
} manera de a cada uno de nosotros. Mientras hacíamos lo nuestro, sabíamos que él estaba haciendo lo suyo. Cuidándonos.

Pero ayer, un llamado tal vez, una persona sospechosa quizás, qué sé yo. Él se hizo presente, como tantas, pero tantas veces. Pero esta vez, dos balazos le madrugaron la espalda. Aquí podría terminar la crónica diaria. Murió el teniente Aldo Garrido en cumplimiento del deber, oficial de la Policía Bonaerense, con 26 años de servicio a punto de jubilarse. Pero no es así. Lo mataron a Garrido, ¿me entendés? Mataron a "nuestro" policía. Al que nos conocía a todos. Al que vimos pasar corriendo mil veces atrás de algún o alguna amiga de lo ajeno. Los detectaba con el olfato, que sólo la experiencia y la vocación dan. Y los disuadía muchísimas veces sólo con la palabra, especialmente si eran criaturas.

[...].

¡Cómo te vamos a extrañar, hermano! Descansá en paz. ${ }^{2}$

Las cámaras enviadas al lugar de los hechos trazaron un panorama contundente. No había vecino que no conociera al policía muerto ni ponderara sus cualidades humanas y profesionales. Interpe-

\footnotetext{
2 "Mataron a Garrido, nuestro policía", carta del lector Luis Uraga, Diario Clarín, de 18 febrero de 2009. Disponible en: http://edant.clarin.com/suplementos/cartas/2009/02/18/CartasAlPais.htm.
} 
lados, repetían una y otra vez los mismos ejemplos: tenía su uniforme siempre impecable y el escudo de su gorra siempre brillante; conocía al detalle todo lo que pasaba en el barrio y se dirigía a los vecinos por su nombre; su presencia tranquilizaba; todos, incluso los descarriados, lo respetaban.

Las expresiones de reconocimiento, consternación y dolor pronto empezaron a viralizarse: los comerciantes bajaron las persianas, los locales de la calle principal lucieron crespones, las vidrieras se llenaron de fotos con su estampa, un florista del barrio regaló las flores que fueran para homenajearlo. ${ }^{3}$

La situación que se vivió con la muerte del teniente Garrido fue sorpresiva y desacostumbrada. En un contexto local habituado a casos generalizados de violencia, brutalidad y corrupción policial - represión de la protesta social, persecución de sectores vulnerables, muerte de detenidos en comisarías, episodios de "gatillo fácil", comisión de ilegalismos, vínculos con el crimen organizado - la imagen policial en Argentina es la de una fuerza bajo sospecha constante. Las razones son complejas y superan el espacio disponible, pero baste señalar que, si bien se trata de cuerpos de seguridad civiles, la normativa y la práctica las han estructurado con esquemas de autori-

\footnotetext{
3 "Fusilan a sangre fría a un policía en pleno centro de San Isidro", Diario Clarín, de 18 febrero de 2009. Disponible en: https://www.clarin.com/policiales/ fusilan-sangre-fria-policia-pleno-centro-san-isidro_0_HkNMYC50TKe.html.
}

dad militar, jerarquías rígidas y sistemas de control interno corporativos y poco transparentes. Sumado a esto, el particular desarrollo histórico-institucional las ha orientado a la represión de las actividades políticas disidentes y del pequeño delito, consolidando una tradición donde el uso de la fuerza es concebido como un ejercicio discrecional y arbitrario que no admite el control externo (Tiscornia, 1998; Martinez y Eilbaum, 1999)4.

En este contexto, no es de extrañar que la imagen policial esté casi en ruinas. El caso del teniente Garrido sacó a la luz, sin embargo - y de modo inusual - una semblanza que resultó contrastante pero no desconocida. Recuerdo a recuerdo, espontáneamente, los vecinos desempolvaron una estampa que el cambio de los tiempos parecía haber vuelto obsoleta: Ia del policía estimado y sentido como propio, la del policía conocedor de su parada y de su gente. En términos policiales, la del viejo "vigilante de la esquina".

En lo que al ámbito local refiere, la costumbre dicta que la muerte de un policía movilice - en el discurso de la propia institución, en la prensa que le hace eco - sentidos asociados al sacrificio, al arrojo, al riesgo del oficio: todo policía que

4 Para mayores datos del contexto policial local, ver Sain (2008), Tiscornia (2008), Frederic (2008) y Pita (2010), entre otros.

5 La frase y su remembranza pronto estuvieron de boca en boca. La prensa rápidamente la puso en marcha. Ver, por ejemplo, "El último vigilante de la esquina", de Fernando Rodríguez, Diario La Nación, de 18 febrero de 2009. Disponible en: http://www.lanacion. com.ar/1100886-el-ultimo-vigilante-de-la-esquina. 
muere en ejercicio de sus funciones es rápidamente transformado en un "caído en cumplimiento del deber" y despedido como un héroe. A la policía le ha gustado, desde antiguo, pensarse en esos términos y hacer de la muerte de los que así mueren una muerte honrosa, al presentarla como una muerte ofrecida. En esos muertos, el sacrificio que le cabe a todo policía alcanza su pico más alto, pues el caído cae en guerra contra el crimen (Galeano, 2011; Sirimarco, 2013a).

La muerte del teniente Garrido podría haber pulsado la cuerda del héroe caído, pero no lo hizo. Y tal vez porque la narrativización de la muerte no cayó en manos de la institución policial sino de la gente ${ }^{6}$, la semblanza del teniente Garrido activó otra figura policial tan mítica como la de los caídos, pero de distinta estirpe; una donde no prima el final, sino la larga trayectoria de un oficio construido cotidianamente. Pues el "vigilante de la esquina", como ha quedado claro, no es cualquier policía que patrulla (ni mucho menos un simple policía que muere), sino uno que construye una relación de especial cercanía y confianza con la comunidad. Uno que inspira y recibe respeto, que se pone al servicio constante de la población y sus problemas, que labra su destino con cada acto de su oficio.

Estos sentidos pueden no ser grandilocuentes, pero así y todo la figura del "vigilante de la esquina" posee una potencia inusitada, en la esfera policial

${ }^{6}$ Volveremos luego sobre ello. argentina, para aglutinar y presentar valores institucionales. Su semblanza es sinónimo del buen quehacer y tiene tal prestigio que no es extraño oírla en boca de policías, todavía hoy, para explicar los bemoles del oficio:

se cree que la policía es corrupta, violenta. Nadie respeta al policía. Pero antes, al policía que estaba en la esquina se lo respetaba, porque era el que cuidaba el barrio, a los chicos cuando jugaban a la pelota. jSi hasta le dejabas las Ilaves de tu casa cuando te ibas de vacaciones!?

La clave de esta semblanza, en lo que al ámbito policial respecta, radica en el antes: su apelación exuda aires de pasado. Su silueta anida, más que en la vida real, en los libros y los recuerdos. Como estas palabras dejan entrever, el "vigilante de la esquina" es, por antonomasia, el policía de los tiempos idos: el funcionario leal y honesto de un paisaje social en que, como se verá, todo era distinto porque todo era mejor.

Este trabajo versa sobre esta figura narrativa. No sobre el teniente Garrido (cuya historia ha servido de disparador y servirá más adelante de punto de tensión) ni sobre cualquier otra historia individual que pareciera confirmarla, sino sobre su existencia misma de relato institucional. Pues el "vigilante de la esquina" es justamente eso: una narrativa que pone en escena discursos, vivencias y valorizacio-

\footnotetext{
7 Subinspector de la PPBA, trabajo de campo correspondiente al año 2014. El argumento es compartido por la mayoría del personal.
} 
nes que permiten pensarse como grupo social y como institución; una matriz de significación que condensa significados, organiza las experiencias y dice a propios y extraños quién y cómo se es.

Como tal, el "vigilante de la esquina" no alude necesariamente a personas reales o sucesos más o menos verdaderos, sino a modelos prototípicos que encarnan mensajes aleccionadores. Porque no hay que olvidar que un relato es una pieza que no está gobernada por la verdad empírica sino por la necesidad narrativa, que pertenece al plano de la interpretación de los hechos y no de su descripción y que lo que prima en ella no es cuánto se acerque o se aleje el suceso narrado de la realidad, sino la realidad que ese suceso narrado ayuda a construir (Bruner, 1991; Ochs y Capps, 1996).

Sostienen Bruner (1998) y Lewkowicz (2008) que toda institución construye relatos que la sostienen; que, para existir como tal, toda institución debe narrarse, es decir, reproducirse. ¿Qué nos dice la estampa del "vigilante de la esquina" sobre la función policial? ¿Qué nos dice acerca del entendimiento de su rol y de su relación con la sociedad? ¿Qué del contexto de descrédito en que esa imagen es fecunda? Este trabajo se propone analizar dicha figura tal como circula en la narrativa policial, reflexionando en torno a material documental y experien cias etnográficas ${ }^{8}$, y como un modo de bucear en las conexiones entre pasado, memoria e identidad que subyacen a la construcción de todo relato institucional. Y en tanto el "vigilante de la esquina" es una figura que se sostiene en la añoranza, este trabajo busca visitar también la ligazón que se construye entre relato y emoción, prestando especial atención al rol de la nostalgia como herramienta inherente a la construcción del pasado.

\section{II}

El "vigilante de la esquina" no es cualquier figura. No explota el abanico habitual de sentidos de lo policial: no se nutre de la fuerza y el coraje, ni del combate al crimen, ni siquiera apela a la muerte heroica y sacrificada. Su potencia de acción nace de la delimitación de una zona con contornos más pedestres. Me gustaría en este apartado repasarlos.

Una buena forma de delimitar esta figura es rastrear los libros de memorias,

8 Las argumentaciones presentes en este artículo están basadas en mi investigación en el ámbito policial, llevada a cabo ininterrumpidamente desde el año 1999 en la Ciudad Autónoma de Buenos Aires y el Gran Buenos Aires. La misma implica una conjunción de trabajo etnográfico - observaciones de campo, entrevistas, registros - y, como se detallará a continuación, análisis documental específico - leyes, reglamentaciones, material de producción institucional, libros de relatos y memorias policiales, etc. 
cuentos y relatos policiales ${ }^{9}$. Estos volúmenes de vivencias y recuerdos se caracterizan por intentar narrativizar, como señalo, la experiencia profesional en base a una serie de tópicos institucionalmente valorados. Escritos a lo largo de una extensa línea de tiempo, tienen en común el uso del medio impreso para bregar por construir el perfil moral del policía ideal, valorizando sus actividades y brindando una "versión oficial" respecto de su labor (Bretas, 2009; Galeano, 2009).

Las escenas que estos libros ofrecen brindan un discurso dispuesto a dialogar con la realidad del momento, a responder agravios y cuestionamientos, a cimentar una buena imagen y a despertar, en el lector, una cierta comunión, educándolo en la comprensión y aceptación de la labor policial, siempre compleja y peligrosa. El "vigilante de la esquina" es, en ellos, una figura recurrente.

Empecemos por revisar un libro temporalmente cercano. En 1999, el comisario Plácido Donato publicó un volumen titulado Las anécdotas de la policía. De vigilantes y ladrones (el género viene cayendo en desuso desde el retorno a la democracia, en la década del ochenta). El prólogo avisa que el libro ha sido urdido para dar a conocer la intimidad del policía, el sacrificio de sus luchas sin tregua, y que en él se recogen anécdotas que son leyenda. El relato "Aquel agente de la esquina" integra este volumen:

9 Por razones de espacio, no es posible extenderme en sus características. Para mayores detalles, ver Sirimarco (2014).
La calle del policía es su universo y él lo sabe [...].

En su natural no violencia, nunca había pisado ni a un sapo saltarín en los zanjones donde transcurrió su infancia y requería para reaccionar ser motivado por un ataque o un insulto. Recién entonces solía ser de lo más drástico y efectivo.

Su trabajo era cuidar los zaguanes, velando en rondas silentes, en un peregrinaje de todos los días, por aquel barrio suburbano donde lo habían destinado a cuidar una singular acuarela de necesidades sociales [...].

Uno de los placeres que su profesión le daba era aquel que hacía a Juan, Adán o el policía, juntarse con la barra en la esquina, bajo el farol, intercambiando opiniones en aquella dialéctica de barrio en donde convivían los Gálvez con los Fangio, María Félix con Esther Williams, Al Jolson y D'Arienzo, Boca y el Resto del Mundo [...].

Jugaba con su silbato golpeándolo en la palma de la mano hueca, haciendo un sonido particular que determinaba su presencia y daba seguridad a esa gente que algunas veces reparaba en él y lo saludaba en el agitado trajinar de cada día. Solía ser el mejor amigo de los chicos y, muchas veces, en su caminar casi soberbio, con un solo gesto les avisaba de la llegada del patrullero que venía a buscar las pelotas que rebotaban inquietando la siesta de la cuadra [.. .]. 
Se llamaba Juan o Adán o el policía... Para la barra era el botón..., el agente...., el cana ${ }^{10}$ de la esquina (Donato, 1999: 161 164).

Resuenan, en el relato de Donato, los rasgos que ya adelantábamos con la semblanza del teniente Garrido: el policía humilde, alejado de la violencia, amigo de la ciudadanía y compinche de los niños. Donato lo dice con otras palabras, que significan lo mismo: "su gigante vestido de azul digno nunca había pisado ni a un sapo saltarín en los zanjones"; intercambiaba opiniones con "la barra en la esquina" y avisaba a los chicos "la llegada del patrullero que venía a buscar las pelotas que inquietaban la siesta".

La lírica de Donato añade otros contornos a la semblanza. Nos dice que el "vigilante de la esquina" es aquel que vela la calle de las afueras: no el centro vertiginoso de la ciudad "sino el barrio suburbano de miserias y riquezas, de culturas y analfabetismos". El "vigilante de la esquina" es el hombre de los contornos, el hombre de la periferia. Donato nos dice también, en concordancia con este contexto sin relieve, que este policía es un hombre común, "un héroe cotidiano, sin mitos ni bronces que enaltezcan su nombre". Podría decirse que es un hombre anónimo - por algo lo llama "Juan, Adán, o el policía" -, y tal vez por eso hasta invisible: a "veces [la gente] reparaba en él y lo saludaba en el agitado trajinar de cada día".

10 Botón y cana: palabras lunfardas para "policía", todavía hoy de uso cotidiano y coloquial.
De los condimentos que ensalzan esta figura, Donato no prescinde del más importante: también su policía de la esquina es un hombre del pasado. "La ciudad creció vertiginosamente", nos dice, y a lomo del progreso este policía digno perdió terreno y terminó habitando los cuentos "que los viejos de hoy le cuentan a sus hijos y a sus nietos". Algunas marcas de época parecen fijar los contornos de ese pasado: el tranvía, Fangio, Williams, Al Jolson. El primero, corredor argentino de automovilismo, se retira en 1958. La segunda, nadadora profesional y actriz, termina su carrera artística en 1963. El tercero, músico, muere en 1950. El tranvía deja de recorrer Buenos Aires en 1963. Así, Juan o Adán o el policía resulta, forzosamente, un hombre de los años 194050, un hombre que vela los zaguanes de los suburbios unos 60 años antes de que Donato le rinda homenaje.

Viajemos un poco más atrás en el tiempo. ¿Qué marcas se guardan, en relatos policiales de años anteriores, sobre el "vigilante de la esquina"? Un nuevo rastreo bibliográfico nos lleva a un libro escrito en 1961: Recuerdos policiales, del comisario Guillermo Rodolfo Anzulovic ${ }^{11}$. Ya desde el prólogo se aclara - reforzando la tesis de que el relato policial es una construcción narrativa y no necesariamente una experiencia oída o vivida - que el protagonista de las historias es

11 El repaso bibliográfico no intenta agotar la totalidad de los registros, sino seleccionar aquellos más relevantes para los propósitos de este trabajo. 
ese policía porteño arquetípico que representa a miles de hombres que han actuado "en tiempos no muy distantes" (Anzulovic, 1967).

El anclaje temporal, impreciso, sitúa las peripecias del policía arquetípico en aquellos "felices tiempos [...] en que los colectivos se detenían en las puertas de los domicilios de los pasajeros" (Anzulovic, 1967: 3) y en los cines siempre se encontraba lugar. La imagen del illo tempore se delinea desde el principio.

Las peripecias laborales que le suceden al protagonista se interrumpen de pronto en el capítulo XXVII, titulado claramente "El vigilante de acero", cuando el autor considera que puede permitirse un

pequeño desvío para reflejar la personalidad de hombres que ocupan el peldaño más bajo de la escalera jerárquica, por ser ellos quienes llevan la representación institucional a las distintas esquinas de la ciudad y enfrentan primero que ninguno, y a veces solos, situaciones difíciles en las que sólo pueden confiar en su propia capacidad y experiencia (Anzulovic, 1967: 147).

Llegado este capítulo, el protagonista abandona el tiempo presente con que venía contando sus historias y en el homenaje al vigilante surgen los verbos en pasado, como si la historia no fuera experiencia cercana sino recuerdo que tuviera que evocarse: nos dice que era un hombre de unos 40 años, de regular estatura, más bien delgado, con 20 años de servicio en la misma parada. Que trabajaba en una comisaría suburbana; que su parada distaba unas 30 cuadras de esa comisaría; que estaba emplazada entre un ramal ferroviario, un arroyo, terrenos descampados y unos ranchos.

Una noche, un oficial se dispuso a controlar dicha parada. Llegó caminando hasta esas lejanías y el protagonista del relato le agradeció el gesto: "pocas veces, ya sea por las lluvias u otras causas, tengo la satisfacción de ver algún superior por estos lados". Avanzada un poco la charla, el oficial le preguntó si le agradaría ocupar otra más poblada y más céntrica:

"Si me ordenan voy a la que me manden, pero en cuanto a gusto, estoy bien aquí."

"No veo la razón de su gusto" —afirmó el oficial.

"Verá señor — dijo aquel apurando su explicación-; esta parada es muy 'brava'. Basta echar un vistazo en esos ranchos para darse cuenta con qué clase de gente hay que tratar, pero yo los tengo 'a raya'12 y si me voy, pensarán 'que me achiqué..."13, perdone el término" —agregó [...].

"De noche tengo que estar atento, pues de los muchos que viven en los ranchos 'unos cuantos son los que andan rateando ${ }^{14}$ por las casas de las inmediaciones y entre ellos hay

\footnotetext{
12 Tener a raya: tener bajo control, controlar.

13 Achicarse: acobardarse.

14 Ratear: robar.
} 
unos pendencieros y cuchilleros. Mi presencia les molesta mucho y hacen lo imposible para alejarme de este lugar, logrando así campo libre para sus actividades delictuosas.

"Algunas veces y sobre todo en los primeros tiempos, cuando me hice cargo de esta parada; en algunas oportunidades estos sujetos, parapetándose en el puente por donde pasan las vías y abajo el arroyo - dijo señalando el lugar -, me han hecho disparos de arma de fuego, con el propósito evidente de hacerme abandonar la parada.

"Comprendí que si les daba el gusto una primera vez, ellos serían los que dominarían siempre la situación, de modo que resolví enfrentarlos; haciendo yo también uso de mi pistola, que de noche llevo en el bolsillo del capote para extraerla con mayor celeridad." (Anzulovic, 1967:147 151).

No había duda alguna, ese agente era en ese lugar el jefe de policía, el intendente municipal... Los vecinos de las inmediaciones lo apreciaban a tal punto que cuando alguna vez se insinuaba la posibilidad de su traslado a otro lugar, ellos mismos se constituían en comisión y ya sea verbalmente o por escrito, no daban tiempo a que se concretara el proyectado pase, pues se dirigían a la comisaría o la jefatura.
Los "cirujas"15 lo temían, pues lo sabían decidido para reprimir cualquier contravención o delito y en general lo respetaban, pues el principio de su autoridad campeaba con su ejemplo de virtudes ciudadanas y profesionales en todo el radio de su acción (Anzulovic, 1967: 147 151).

Reaparecen, en este relato, los trazos que enfatizaba Donato: el hombre anónimo y común, que actúa en solitario y enfrenta primero que ninguno y a veces solo las situaciones difíciles de la calle. Reaparece también el suburbio: emplazada entre ranchos, vías y descampados, a la parada de este policía sólo se llega a caballo o a pie, siempre y cuando la lluvia y el barro no lo impidan. La parada está distante y aislada, y esta distancia y este aislamiento son literales y metafóricos.

Literal, porque a 30 cuadras de la comisaría y a 10 de la parada más próxima, en la parada de nuestro vigilante reinan la oscuridad y el canto de las ranas. Metafórico, porque todavía más allá de una comisaría ya suburbana, la parada en cuestión se vuelve suburbio del suburbio, y en ese movimiento de ir cada vez alejándose, el desplazamiento geográfico se tiñe de temporal, como si lo que pasara lejos pasara en el pasado. Se nos dice vagamente que todo sucede en tiempos no muy distantes - recordemos que estamos en los años 1960 -, pero las huellas que se escancian a lo largo

15 Ciruja: mendigo. 
del texto - el barro, las ranas, el arroyo, el hombre a caballo, los cuchilleros - confabulan para presentar la imagen de un tiempo largamente ido. La construcción del paisaje suburbano que es propia del "vigilante de la esquina" se vuelve, en este relato puntual, aun más bucólica.

Reaparece aquí también otro rasgo clave de esta figura: su valía entre vecinos y maleantes. Anzulovic dice que los primeros "lo apreciaban" tanto que ni bien se insinuaba la posibilidad de su traslado, se dirigían a la jefatura para que no se concretara el proyecto. Y que los segundos "lo temían y lo respetaban", conocedores de su autoridad y su firmeza para reprimir delitos.

La semblanza de Anzulovic abreva en estos sentidos - el policía incorruptible ante la delincuencia, como dirían Garriga Zucal y Melotto (2013) - pero echa en falta al "vigilante de la esquina" como compinche de niños y vecinos. Y tal vez esta ausencia de evocaciones de corte sensible - los chicos jugando a la pelota, el policía charlando con la barra - no sea un detalle menor. Sobre todo si se aúna a otro rasgo que en este relato destaca contrastivamente: el sentido de servicio de este "vigilante de la esquina" no excluye necesariamente el uso de la fuerza.

Decía antes Donato que el policía de su relato nunca había pisado ni a un sapo en los zanjones de su infancia. Decía también que para llegar a reaccionar tenía que ser motivado (Donato, 1999: 161). Decía entonces que el uso (legítimo) de la fuerza no estaba descartado, pero en un movimiento de prestidigitación nos lo ocultaba. La sentencia quedaba sugerida, pero no mostrada: ninguna de las imágenes construidas nos presentaba al policía en alguna situación de esa índole. Antes bien, el policía de Donato intercambiaba opiniones bajo el farol, mostraba la foto de sus hijos con orgullo y evitaba que los chicos perdieran sus pelotas cuando jugaban al futbol en la calle.

La misma fuerza legítima pone en juego el vigilante de Anzulovic, pero ya sin ocultarla. Más bien lo contrario: se diría que el respeto que se gana este policía gira en torno a estas acciones - tiros, enfrentamientos, persistencia en la paradacomo si el principio mismo de la autoridad policial se fundara sobre la "bravura" $y$ ésta no tuviera que ser escamoteada, sino puesta en primer plano. Si el policía de Donato hacía hincapié en lo policial como servicio comunitario, el vigilante de Anzulovic, sin abandonar estos valores, enraíza su función en el combate al crimen.

Vemos que los puntos de contacto entre ambas figuras son claros, pero los corrimientos de sentido también son visibles y conducen a una pregunta: ¿es el policía de Anzulovic el mismo policía de Donato? ¿Aluden a una misma semblanza? La respuesta es compleja y requiere de salvedades.

La primera, que un relato no es una pieza acabada. Antes bien, un relato es una pieza narrativa colectivamente producida, resultado de la intervención de 
diversos materiales, personas, tiempos y objetivos (Ewick y Silbey, 1995; Hohr, 2000). Lo que significa que un relato se caracteriza entonces por contener huellas de variaciones. Esas discordancias no debieran sorprendernos. Un relato se teje con innumerables puntadas, y los nudos divergentes no anuncian la invalidez de la trama, sino su riqueza y el hecho mismo de su factura. Las variaciones están ahí para recordarnos que un relato es un artefacto que fue (re)hecho innumerables veces, que fue manipulado, cambiado, re-narrado, que porta, en síntesis, un tipo particular de manufactura y de historicidad (Alberti, 2005; Gomes da Cunha, 2010).

La segunda salvedad: que un relato es deudor de su construcción en tiempo presente. Y su anclaje, por más que intente presentarse como un recuerdo "puro" del pasado, conlleva siempre el caudal interpretativo del aquí y ahora, que modela su modo de ser contado, sus significados y sus efectos (Ewick y Silbey, 1995). La relación de las representaciones pasadas con las actuales está simbólicamente mediada y los elementos que se rescatan para conformar un relato se encuentran en función de los intereses y necesidades del contexto contemporáneo (Frank, 1979; Piña, 1986; Linde, 1993; Barnes, 1995; Cavallaro, 2000).

A la luz de estos argumentos, conviene revalidar la pregunta: ¿aluden los policías de Donato y de Anzulovic a la misma semblanza? ¿Hacen referencia ambos al famoso "vigilante de la esquina"? Los títulos de ambos relatos parecen confirmarnos en esa línea, así como la voluntad de presentarnos a los protagonistas en su accionar cotidiano. Si la descripción de ambos pudiera reducirse a unos pocos trazos, coincidiría en un mismo perfil: el suboficial de experiencia cuyo sitio es la calle y su honor el cuidado de bienes y vecinos.

En este contexto, los diversos matices del relato bien podrían entenderse, más que como discrepancias radicales o estadios de una historia que evoluciona cronológicamente, como variaciones en torno a una cierta línea temática, con la licencia propia que da cada tiempo. La siguiente constatación no busca ser determinante ni conclusiva, pero tal vez no haya que olvidar que el policía de Donato mira al pasado desde 1999, a 16 años de la última dictadura militar, en un tiempo de reformas policiales. El policía de Anzulovic, por el contrario, ve la luz cuando el país acaba de entrar a un nuevo período dictatorial que duraría siete años. ¿Cuánto de ese giro hacia el uso de la fuerza es deudor del perfil policial que soportaba la época?

Un nuevo buceo retrospectivo podría añadir luz a la incógnita, pero la figura del "vigilante de la esquina" no vuelve a encontrarse en memorias policiales de años anteriores. Los libros son muchos al inicio del siglo XX, pero la mayoría se aboca a la tipología de delincuentes o a la biografía de policías célebres. Pocos son los que relatan anécdotas del oficio y, en éstos, las referencias a policías de tales caracte- 
rísticas no aparecen. Aparece levemente, sí, en el recuento de los años 1914-191616, la figura del vigilante, pero la semblanza está allí con la intención de mostrar a un funcionario cuya riqueza mayor radica en su honestidad y su simpleza, y que no aparece desarrollando acto policial alguno. Mucho menos aparece la semblanza "el vigilante de la esquina" en memorias más decimonónicas.

Tal vez la figura se haya ido diluyendo (tal vez esta semblanza del vigilante simple-pero-honesto fuera una variación más del tópico que se aggiornaría luego con el condimento comunitario), tal vez la figura sólo haya nacido y vivido en un período determinado ${ }^{17}$, tal vez yo no haya sido capaz de dar con otros libros que hubieran podido poner en cuestión estas sentencias. En todo caso, llegados a este punto, creo que las referencias esgrimidas bastan para habilitar algunas conclusiones. Me gustaría señalar dos, ambas obvias y visitadas, pero necesarias para continuar el argumento.

La primera: que la figura del "vigilante de la esquina" siempre sucede en el pasado. Lo encontramos en un volumen de 1999 haciendo referencia aproximada a los años 40-50, y antes en un volumen de 1961 aludiendo explícitamente a un pasado "no muy distante" pero insinuando

\footnotetext{
16 A. Donadio, Noticioso policial, 1943, Buenos Aires, Ediciones Anaconda.

17 Caimari (2012) sitúa la consolidación de esta figura en el período de entreguerras, como una versión local del más genérico policía "comunitario" que aparece por entonces en otras ciudades del mundo.
}

sin embargo un pasado aun más remoto. Y lo curioso es que la remisión al pasado nunca se rompe: el "vigilante de la esquina" siempre está más allá de donde lo buscamos, su anclaje continúa cayendo hacia atrás.

De lo que se desprende la segunda conclusión: que su figura no habita en el pasado, sino en el tiempo mítico, es decir en el tiempo irreal. El "vigilante de la esquina" es un relato construido para no poder narrarse en sincronía. De esta característica fundamental extrae su potencia discursiva: del recuerdo constante de un pasado glorioso, de la añoranza del orden moral que alguna vez tuvimos (Caimari, 2012; Garriga Zucal y Melotto, 2013; Sirimarco, 2014). Si algo caracteriza al "vigilante de la esquina" es entonces su esencia de habitar en lo lejano. O más bien en lo inasible. Es decir, en la nostalgia.

III

El término nostalgia fue acuñado en el siglo XVII por un estudiante de medicina, Johannes Hofer, a partir de las palabras griegas nostos, volver a casa, y algos, dolor. Refiere, literalmente, al dolor por el hogar, e intentaba en ese momento dar nombre a la extraña melancolía que sufrían los soldados suizos que servían en el extranjero, obsesionados con el deseo de retornar. Fue por eso, en sus orígenes, una categoría médica y de raigambre en el cuerpo físico. Con el correr del tiempo, sin 
embargo, extendió su sentido de "añoranza por el hogar" a otra multiplicidad de situaciones, hasta pasar a significar, de modo más abarcativo, el anhelo de retorno a circunstancias pasadas y de allí, también, en un nuevo salto a lo metafórico, el deseo de un lugar perdido, ya sea real o imaginado (Beller, 1996; Fritzsche, 2001; Boym, 2007; Farrar, 2011).

En ese espacio habita el "vigilante de la esquina": en uno construido a fuerza de pérdida y objeto elusivo, en uno que atesora el pasado por cualidades que ya no están y añora aquello que no puede ser restaurado. Si en el apartado anterior revisábamos este relato desde sus contornos policiales, me gustaría ahora profundizar en el mensaje específico que se despliega a través de la visitación de la nostalgia, otra vez al interior de esos contornos. ¿Qué transmite este sentimiento del modo de construir la memoria, la identidad y, en definitiva, la institucionalidad? ¿De qué habla un relato que se vertebra a partir de este sentimiento? ¿Qué clase de pasado evoca y para qué?

A simple vista, y en tanto habitante de un mundo lejano y candoroso, la clave del "vigilante de la esquina" parece esconderse en el pasado. Se oculta, sin embargo, en el presente, o más bien en un espacio a caballo de los dos. "La vida no es la que uno vivió", dijo alguna vez García Márquez, "sino la que uno recuerda para contarla". Lo que equivale a decir que toda memoria - todo pasado - se construye desde los intereses del presente. $Y$ en esto radica la fuerza emocional y arrolladora de la nostalgia. En tanto nexo capaz de ligar - de un modo particular - el pasado con el presente (y por ende con el futuro), su carga semántica resulta funcional a la construcción de la memoria y la identidad, individual y colectiva. La nostalgia opera a través de una particular concepción del ayer, del hoy y de su enlace. Pero vayamos por partes.

La nostalgia propone, en primer lugar, una clase determinada de pasado. El relato del "vigilante de la esquina" es claro: el pasado se presenta como el locus de lo ido, de lo perdido. Los chicos jugando en la calle, los vecinos confiando las llaves de sus casas, los delincuentes respetando la autoridad: todo parece haber quedado atrapado en un lugar que ya está más allá de nuestro modo de vida. El pasado se configura así como el espacio de lo irrecuperable.

Pero si el ayer sólo puede re-visitarse desde el ahora, ¿qué clase de presente queda enmarcado por un pasado semejante? O mejor dicho: ¿qué es lo que sucede en el presente para proyectar, sobre el pasado, una mirada de ese tipo? La nostalgia requiere, en segunda instancia, una contemporaneidad atravesada por el desencanto, desde la cual la mirada de añoranza cobre sentido. Ésta parece resultar inentendible sin un contexto contemporáneo en declive, sin un escenario que haga necesario re-visitar lo ido para afirmar la pérdida (Fairley, 2003; Bissell, 2005).

Pero la nostalgia, más que delimitar un pasado y un presente, delimita una ruptura. O mejor dicho: construye un hiato ca- 
paz de producir dos momentos temporal y socialmente diferenciados. La nostalgia, y ésta es su característica primigenia, es la instauración de un quiebre. Y esto en dos órdenes de sentido. El primero, claramente temporal, deudor de una concepción de proceso histórico como producción continua de lo nuevo, donde el flujo del tiempo corre lineal y unidireccionalmente. El segundo, montado sobre el primero, de corte si se quiere moral, donde el flujo temporal, además de ser irrecuperable, se tiñe de pérdida (Fritzsche, 2001; BisseII, 2005). Esto logra el relato del "vigilante de la esquina": nos habla de la existencia de ese policía de antaño, pero además, y sobre todo, nos habla de lo triste e irremediable de su falta. En eso radica la estrategia de la nostalgia: en sumarle, a un tiempo necesariamente ido, la eventualidad de su añoranza; en hacer de la imposibilidad del retorno un motivo de deseo. Porque el retorno puede ser imposible, pero el ansia de regreso es opcional. La nostalgia parece haberse inventado para regodearse en ese quiebre.

De esa amalgama de tiempos discontinuos, la nostalgia construye su potencia, estableciendo continuidades a partir de las rupturas. Entre el ayer y el hoy, entre el vigilante de antes y el policía de ahora. Yendo y viniendo del pasado al presente, la nostalgia no hace sino permitirnos ser transportados al lugar que recordamos, creando así un sentido de lugar en los alrededores de uno. Es decir, sirviendo de conexión con el pasado y entramando, en un colectivo mayor, los hilos individuales de la historia de una vida (Batcho, 2007; Farrar, 2011). La nostalgia opera así entre junturas: de tiempo, pero también de identidades, sirviendo de ajuste entre la biografía individual y la biografía de los grupos, entre la memoria personal y la memoria colectiva.

Es por eso que el "vigilante de la esquina", como todo relato institucional, deviene un insumo clave en el proceso identitario ${ }^{18}$, al colaborar en la construcción de una memoria grupal forjada a fuerza, entre otras cosas, de revivir experiencias pasadas (reales o ficticias). La figura de ese vigilante aglutina mojones de sentido: las vivencias del ayer, determinadas por las necesidades del presente y a su vez enmarcándolo, funcionan como recuerdo colectivo: evocar su figura y sus virtudes es esforzarse en forjar un sentido compartido de identidad grupal (Fairley, 2003; Bissell, 2005; Farrar, 2011). Baste si no reparar en la nostalgia de los soldados suizos y entender que se trataba, en última instancia, de una estrategia de supervivencia, de un modo de dotar de sentido a la imposibilidad de volver a casa. Cosa semejante ocurre con el "vigilante de la esquina": la nostalgia por ese policía no es más que un modo entre otros de elaborar un pasado en estrecha vinculación con el presente; es decir, de producir memoria y comunidad.

¿Qué clase de memoria, sin embargo, construye un relato que pivotea tan fuer-

18 Aludo al plano de su pretensión, no necesariamente de su aceptación. Para mayores detalles, ver Sirimarco (2013b). 
temente en torno a la nostalgia? Remarca Batcho (2007) que se puede recordar sin ser nostálgico, pero no se puede ser nostálgico sin recordar: la nostalgia es una fuerza emocional que permite ciertos tipos de reminiscencia, que resulta funcional al entendimiento de ciertos eventos. La construcción nostálgica del pasado encierra sentidos de tono particular. ¿Qué nos dice, el uso de la nostalgia, sobre la construcción del pasado y el presente de la institución policial?

Las conclusiones son al menos tres y son a este punto evidentes. El relato del "vigilante de la esquina" resulta funcional, en primer lugar, a un presente profesional de descréditos. Con su honestidad y su autoridad ganada a fuerza de decencia, este policía de antaño se erige como el espejo embellecedor donde resolver las imágenes controversiales del ahora. A la mala policía del presente se le opone el vigilante de un pasado feliz, convirtiéndolo así en prenda de un consenso que logra quedar por encima de las denuncias que cruzan el hoy de la institución (Isla, 2004; Caimari, 2012).

No casualmente se ha señalado que los brotes de nostalgia siguen a menudo a los períodos de crisis - la Revolución Francesa, la Revolución Rusa, los soldados suizos en el extranjero, los contextos coloniales (Rosaldo, 1989; Bissell, 2005; Boym, 2007) -, como si un presente en convulsiones requiriera una estrategia emocional elusiva para hacerle frente. Semejante hipótesis le cuadra al relato del "vigilante de la esquina", lo que nos conduce a la segunda conclusión: su figura resulta funcional al enmascaramiento de relaciones de desigualdad. Repárese, si no, en las líneas precedentes: revoluciones, imperialismos, guerras. La nostalgia parece surgir allí donde sea necesario suprimir observaciones dolorosas.

"La nostalgia es una emoción particularmente apropiada de invocar para intentar establecer la propia inocencia y al mismo tiempo hablar sobre lo que uno ha destrozado" (Rosaldo, 1989: 108). Sobre esa estrategia se monta también el relato del "vigilante de la esquina". Echa de menos las virtudes perdidas, pero denuncia al mismo tiempo, implícitamente, que esa falta es responsabilidad de cualquiera menos propia - del progreso, de la sociedad, de la vida. La nostalgia, diría Rosaldo, opera enmascarando compromisos; encubriendo, bajo una mirada edulcorada e indulgente, la responsabilidad por las acciones propias.

La nostalgia resulta, entonces, una fuerza emotiva de gran potencia para escapar de una situación disconforme. El escape, es evidente, se realiza hacia un aspecto más positivo de esa identidad amenazada: se realiza hacia el pasado irrecuperable. La nostalgia resulta funcional, entonces, y en tercer lugar, a la construcción de un pasado mítico, en tanto su tendencia no es la búsqueda de un tiempo perdido, sino la sustitución de la memoria por un pasado ficcionalizado y retocado, la sustitución de la experiencia por la ilu- 
sión (Beller, 1996). ¿Qué otra cosa, si no, es la figura del "vigilante de la esquina" y su evocación de aquel policía amigo y valorado, de aquella sociedad más inocente, de aquel coqueteo con la fantasía de todo tiempo pasado como intrínsecamente mejor? La operación es clara: la visitación de esta figura permite a la institución policial asegurar, en un tiempo legendario, aquello que ya no encuentra en el presente ni volverá a encontrar en el futuro (y que tal vez nunca haya tenido en el pasado). La nostalgia convierte dicho pasado en un campo de invención, transformando la ausencia en pérdida. Es decir, haciendo que algo inexistente aparezca como algo que se perdió.

En este sentido, la mirada nostálgica es aquella que anhela volver a donde nunca estuvo. Lo que nos lleva a sospechar que lo que importa en ella no es tanto la vuelta al pasado, sino la necesidad de volver: no la añoranza de un referente concreto, sino la añoranza de la fuga en sí. La mirada nostálgica se regodea en la evasión. No propone - para retomar nuestro caso - un tipo de actuación policial que se desea conseguir, sino un modelo inalcanzable que se pueda seguir añorando. Esto es, que pueda seguir habitando en ese horizonte ideal al que no llegan las manchas del presente.

Podrá decirse, sin embargo, que la figura del "vigilante de la esquina" se utilizó, en el caso del teniente Garrido, no para aludir a un policía del pasado, sino a un policía contemporáneo. Así, un caso que se había revelado inicialmente productivo para servir de puntapié a la reflexión de estas cuestiones, parecería ahora contradecirlas. Esta tensión, me parece, es sin embargo aparente, y despejarla requiere realizar un movimiento aclaratorio. Para ello, es preciso resaltar el hecho de que tal figura, en lo que a este caso respecta, fue espontáneamente evocada por los vecinos de la zona, valiéndose desde ya de ciertos sentidos presentes en el relato institucional - la honestidad, la cercanía a la comunidad, la no violencia - pero sin retomar de él cuestiones más puntuales como el posicionamiento de este funcionario en un pasado evocado y nostálgico. En este sentido, resulta significativo comprobar que la propia institución no intentó homenajear al teniente Garrido con esta semblanza (ni tampoco con otras relativas a la heroicidad o la muerte en cumplimiento del deber). Por el contrario, obturó cualquier modo de narrativizar su vida o su muerte.

En un trabajo que pasa revista a estos acontecimientos, Galvani y Maglia (2017) remarcan cómo la muerte del teniente Garrido no fue apropiada por la PPBA: en su tumba, sólo por dar un ejemplo contundente, no hay rastros institucionales - escudo, bandera, placa - que lo recorten como policía. Y así como querido por la gente, señalan las autoras, también era desfavorablemente visto por los colegas: lejos de considerarlo un par, lo veían como un "privilegiado" que no estaba sometido a la regulación laboral y 
jerárquica en la que ellos se encontraban (trabajaba en horario comercial y pasaba por la comisaría sólo para "fichar") ni se encontraba expuesto a situaciones de peligro. Esta situación ventajosa, insinuaban los colegas, se debía a contactos políticos que lo habían mantenido 26 años trabajando en las mismas manzanas y en una zona bastante segura, por fuera del juego de los pases, destinos y tareas adicionales que el resto de sus compañeros debía cumplir, y haciendo posible así un modo de policiamiento prácticamente inviable en el contexto presente.

Así, donde los vecinos veían un policía querido, cercano y arraigado en la comunidad, los policías de la zona veían un compañero ausente, privilegiado y no necesariamente solidario. Si los vecinos veían en su presencia una garantía de protección, los policías veían una zona comercial mayormente segura, con o sin la vigilancia del teniente. Los vecinos veían en él un modo de policiamiento concretamente posible, los policías, una modalidad de trabajo virtualmente impracticable por fuera de dispensas políticas. Para unos, era motivo de exaltación; para otros, causa de descrédito. La semblanza del policía honesto y respetado que veían unos llevaba en sí la semblanza que veían otros: la del policía "acomodado".

No se trata, desde ya, de visiones contradictorias sino complementarias. O, en todo caso, de zonas privilegiadas de visión. Se entiende sin embargo que la aparente contradicción de contar con un policía del pasado enraizado en el presente sólo es tal al poner lado a lado dos ámbitos diferenciales en que esta figura se apropia y circula. El accionar del teniente Garrido puede ligarse, para los vecinos, al antiguo "vigilante de la esquina", pero difícilmente podría haber sido recuperado en esos términos por la propia institución, pues adolece del contexto adecuado que vuelve a esta figura honrosa y valorada. La contradicción se disipa, entonces, al entender que proviene de la contrastación de dos esferas de significación diferentes ${ }^{19}$. Para la lógica policial, la asimilación del teniente Garrido a la figura del "vigilante de la esquina" sigue siendo, creo yo, una empresa rechazada, en tanto no se ve allí el buen quehacer de un funcionario común y corriente, sino el oficio infrecuente de un policía con prebendas. El caso del teniente Garrido, aclamado por los vecinos pero desestimado por los propios colegas, parece entonces confirmar, más que contradecir, al "vigilante de la esquina", al menos en términos estrictamente policiales, como una figura imposible de cuajar en el presente, toda vez que ese modo de policiamiento es ya "honesta"

19 Ponerlas en relación implica un ejercicio sumamente interesante, que permite vislumbrar los procesos mediante los cuales se produce, circula, se comparte y se re-significa un determinado relato a través de diversos niveles y ámbitos de análisis. Una profundización en tal sentido excede, sin embargo, los ejes de este trabajo. 
y generalizadamente impracticable ${ }^{20}$. La figura del "vigilante de la esquina", tal como el relato policial lo entiende, sigue siendo la del policía de un pasado mítico, la de un policía cuyo proceder idealizado sigue dando cauce al desengaño.

De allí que sostenga que el "vigilante de la esquina", como todo relato nostálgico, no pueda existir en lo simultáneo. Y de allí que la nostalgia se vuelva una herramienta política central en la manufactura de memorias y relatos, pues parecería tener un valor específico en la construcción de "ficciones tranquilizadoras". La figura de ese policía inviste la actividad policial con valores de honestidad y respeto, pero su semblanza no es sino una alfombra cómoda bajo la cual barrer la realidad de un sistema recelado. La activación de su discurso intenta esquivar las vicisitudes del presente a través de la rememoración de un pasado dorado. Intenta clausurar la emergencia de una situación problemática con la instalación de una historia mítica.

Después de todo, la nostalgia siempre ha sido, desde aquellos primeros soldados suizos hasta ahora, una estrategia de supervivencia. Una operación semántica tendiente a administrar memorias, signi-

\footnotetext{
20 Lo que demuestra además que la vehiculización de un relato no es un proceso lineal sino arbitrario, y que la voluntad institucional de hacerlo circular en referencia a personas concretas siempre está en relación a lazos profesionales y afectivos. El silencio oficial que la PPBA mantuvo respecto a la muerte de Garrido parece estar en concordancia con el sentir policial que recogen Galvani y Maglia (2017) en su trabajo.
}

ficados y relaciones sociales. Esto es, una herramienta política. El recurso, desde ya, no es monopolio exclusivo de la fuerza policial, sino que habita toda institución o grupo que busque significar la pérdida. En el contexto policial, las complejas variables de su historia y su presente han hecho de la figura nostálgica del "vigilante de la esquina" un insumo que opera, mayormente, como espacio de reivindicación y posicionamiento. Para eso interesa la nostalgia: para facturar un estado de bonhomía profesional inexistente. Porque ya lo dijo Marcel Proust famosamente: los únicos paraísos reales son los perdidos.

\section{Referencias bibliográficas}

Alberti, S. 2005. Objects and the Museum. Isis, 96(4): 559-571. DOI: 10.1086/498593.

Anzulovic, G. R. 1967. Recuerdos policiales. Buenos Aires, Ediciones Macchi.

Barnes, H. 1995. Interpretando leyendas urbanas. In: Blache, M. (comp.) Narrativa folklórica (II). Buenos Aires, FADA: 72-95.

Batcho, K. 2007. Nostalgia and the emotional tone and content of song lyrics. The American Journal of Psychology, 120(3): 361-381. URL estable: http://www.jstor. org/stable/20445410.

Beller, S. 1996. The world of yesterday revisited: nostalgia, memory and the Jews of finde-siècle Vienna. Jewish Social Studies, 2(2): 37-53. URL estable: http://www.jstor. org/stable/4467470. 
Bissell, W. 2005. Engaging colonial nostalgia. Cultural Anthropology, 20(2): 215-248. DOI: 10.1525/can.2005.20.2.215.

Boym, S. 2007. Nostalgia and its discontents. The Hedgehog Review, 9(2): 7-18. Disponible en https://pdfs.semanticscholar.org/ cfcb/eba8cb80315ffebfcf16fe4d17fa6f31286e.pdf.

Bretas, M. L. 2009. Revista policial: formas de divulgação das policías no Rio de Janeiro de 1903. História Social [Online], 16: 87104. Disponible en: https://www.ifch. unicamp.br/ojs/index.php/rhs/article/ view/235.

Bruner, J. 1991. The narrative construction of reality. Critical Inquiry, 18(1): 1-21. DOI: 10.1086/448619.

Bruner, J. 1998. What is a narrative fact? The Annals of the American Academy of Political and Social Science, 560(1): 17 27. DOI: 10.1177/0002716298560001002.

Caimari, L. 2012. Mientras la ciudad duerme. Pistoleros, policías y periodistas en Buenos Aires, 1920-1945. Buenos Aires, Siglo XXI.

Cavallaro, R. 2000. Sociologia e storie di vita: "il testo", il "tempo", lo "spazio". Biografia, storia e societá. In: Macioti, M. I. (comp.) L'uso delle storie di vita nelle scienze sociali. Napoli, Liguori: 57-72.

Donato, P. 1999. "Aquel agente de la esquina". In: Las anécdotas de la policía. De vigilantes y ladrones. Buenos Aires, Editorial Planeta.

Ewick, P.; Silbey, S. 1995. Subversive stories and hegemonic tales: toward a sociology of narrative. Law \& Society Review, 29(2): 197226. DOI: 10.2307/3054010.

Fairley, S. 2003. In search of relieved social experience: group-based nostalgia sport tourism. Journal of Sport Management, 17(3): 284-304. DOI: 10.1123/jsm.17.3.284.
Farrar, M. 2011. Amnesia, nostalgia and the politics of place memory. Political Research Quarterly, 64(4): 723-735. DOI: 10.1177/1065912910373553.

Frank, G. 1979. Finding the common denominator: a phenomenological critique of life history method. Ethos, 7(1): 68-94. DOI: 10.1525/eth.1979.7.1.02a00050.

Frederic, S. 2008. Los usos de la fuerza pública. Debates sobre militares y policías en las ciencias sociales de la democracia. Biblioteca Nacional - Universidad Nacional de General Sarmiento, Buenos Aires, Los Polvorines.

Fritzsche, P. 2001. Specters of history: on nostalgia, exile and modernity. The American Historical Review, 106(5): 1587-1618. DOI: $10.2307 / 2692740$.

Galeano, D. 2009. Escritores, detectives y archivistas. La cultura policial en Buenos Aires, 1821-1910. Buenos Aires, Teseo.

Galeano, D. 2011. "Caídos en cumplimiento del deber". Notas sobre la construcción del heroísmo policía. In: Galeano, D. y Kaminsky, G. (coords.) Mirada (de) uniforme. Historia y crítica de la razón policial. Buenos Aires, Teseo: 185-219.

Galvani, M.; Maglia, E. 2017. "Héroe es otra cosa". In: Garriga Zucal, J. (ed.) "Sobre héroes y tumbas". Sacrificio, heroísmo y martirio en las fuerzas de seguridad. Buenos Aires, Octubre Editorial.

Garriga Zucal, J.; Melotto, M. (2013) La diversidad (in)visible. Identidad(es) entre policías bonaerenses. Avá, 22: 77-96. Disponible en: http://www.ava.unam.edu.ar/index. php/ava-22. 
Gomes da Cunha, O. M. 2010. La existencia relativa de las cosas (que reposan en los archivos): prácticas y materialidades en relación. In: Sirimarco, M. (comp.) Estudiar la policía. La mirada de las ciencias sociales sobre la institución policial. Buenos Aires, Teseo: 97-138.

Hohr, H. 2000. Dynamic Aspects of Fairy Tales: Social and emotional competence through fairy tales. Scandinavian Journal of Educational Research, 44(1): 89-103. DOI: 10.1080/713696665.

Isla, A. 2004. La calle, la cárcel y otras rutinas de los ladrones. Tradición y cambio en el mundo del delito. In: Dammert, L. (ed.) Seguridad ciudadana, experiencias y desafíos. Valparaiso, Municipalidad de Valparaíso: 17-27.

Lewkowicz, I. 2008. Pensar sin Estado. La subjetividad en la era de la fluidez. Buenos Aires, Paidós.

Linde, C. 1993. Life stories. The creation of coherence. New York, Oxford University Press.

Martinez, J.; Eilbaum, L. 1999. La violencia policial en Argentina. Una debate sobre las visiones del problema y las políticas posibles. In: Proyecto Policía y Sociedad Democrática. CELS, Viva Rio-ISER, CED.

Ochs, E.; Capps, L. 1996. Narrating the self. Annual Review of Anthropology, 25: 19-43. DOI: 10.1146/annurev.anthro.25.1.19.

Piña, C. 1986. Sobre las historias de vida y su campo de validez en las ciencias sociales. Revista Paraguaya de Sociología, 23(67): 143-162.

Pita, M. V. 2010. Formas de morir y formas de vivir. El activismo contra la violencia policial. Buenos Aires, Editores del Puerto \& CELS.
Rosaldo, R. 1989. Imperialistic nostalgia. Representations, 26: 107-122. DOI: doi. org/10.2307/2928525.

Sain, M. 2008. El Leviatán azul. Policía y política en la Argentina. Buenos Aires, Siglo XXI.

Sirimarco, M. 2013a. Reformas policiales y narrativas institucionales en Argentina. Renombrando escuelas de policía. DADOS Revista de Ciências Sociais, 56(3): 605-633. DOI: 10.1590/S0011-52582013000300005.

Sirimarco, M. 2013b. A vida com farda. A vestimenta policial como relato institucional em disputa. Revista Brasileira de Ciências Sociais, 28(82): 31-43. DOI: 10.1590/S010269092013000200003.

Sirimarco, M. 2014. La moral en entredicho. Policía y moralidad en libros de relatos institucionales. Iberoamericana, 14(54): 27-43. DOI: 10.18441/ibam.14.2014.54.27-44

Tiscornia, S. 1998. Violencia policial. De las prácticas rutinarias a los hechos extraordinarios. In: Izaguirre, I. (comp.) Violencia social y derechos humanos. Buenos Aires, Eudeba: $125-145$

Tiscornia, S. 2008. Activismo de los derechos humanos y burocracias estatales. El caso Walter Bulacio. Buenos Aires, Editores del Puerto \& CELS. 